\title{
Upfront treatment with the first and second-generation tyrosine kinase inhibitors in Ph-positive acute Iymphoblastic leukemia
}

\author{
Guopan $\mathbf{Y u}^{1,{ }^{1},}$, Fang Chen ${ }^{1, *}$, Changxin Yin ${ }^{1}$, Qifa Liu ${ }^{1}$, Jing Sun ${ }^{1}$, Li Xuan ${ }^{1}$, Zhiping \\ Fan ${ }^{1}$, Qiang Wang ${ }^{1}$, Xiaoli Liu ${ }^{1}$, Qianli Jiang ${ }^{1}$ and Dan $X \mathbf{u}^{1}$ \\ ${ }^{1}$ Department of Hematology, Nanfang Hospital, Southern Medical University, Guangzhou, China \\ *These authors have contributed equally to this work \\ Correspondence to: Dan XU, email: xudan2@medmail.com.cn \\ Keywords: tyrosine kinase inhibitor; BCR/ABL; acute lymphoblastic leukemia; efficacy; safety \\ Received: May 18, $2017 \quad$ Accepted: September 08, $2017 \quad$ Published: October 31, 2017 \\ Copyright: Yu et al. This is an open-access article distributed under the terms of the Creative Commons Attribution License 3.0 (CC \\ BY 3.0), which permits unrestricted use, distribution, and reproduction in any medium, provided the original author and source are \\ credited.
}

\section{ABSTRACT}

The treatment of Ph-positive acute lymphoblastic leukemia ( $\mathrm{Ph}+\mathrm{ALL})$ has entranced tyrosine kinase inhibitors (TKIs) era. Currently both imatinib and dasatinib are registered as the front-line treatment for $\mathbf{P h}+\mathbf{A L L}$, and the other $\mathbf{2}^{\text {nd }}$-generation TKIs are suggested as an alternative for those who failed the first-line treatment. However, it remains unclear who could benefit from the $2^{\text {nd }}$-generation TKIs as the first-line treatment for Ph+ ALL. In this study we compared the efficacy and safety of the $1^{\text {st }}$ and $2^{\text {nd }}$-generation TKIs in the front-line treatment of Ph+ ALL and found a trend toward better disease-free survival (DFS) in the $2^{\text {nd }}$-generation TKIs group, though no significant difference in early response and long-term survival between the two groups. Furthermore, subgroup analysis showed that if allogeneic hematopoietic stem cell transplantation (allo-HSCT) was incorporated as consolidation, the $\mathbf{2}^{\text {nd }}$ generation TKIs benefited patients with better DFS and overall survival (OS). The two generation TKIs were well tolerated. Higher incidence of acquiring T315I mutation was observed in the patients relapsed on the $2^{\text {nd }}$-generation TKIs. These findings suggested front-line treatment of $\mathrm{Ph}+\mathrm{ALL}$ with the $2^{\text {nd }}$-generation TKIs might benefit patients with better survival when allo-HSCT was incorporated as consolidation therapy; meanwhile, the higher incidence of T315I mutation in patients relapsed on the $2^{\text {nd }}$-generation TKIs deserved further attention.

\section{INTRODUCTION}

The Philadelphia chromosome $(\mathrm{Ph})$, resulting from fusion of $B C R-A B L$ gene, is the most common cytogenetic abnormality in adult patients with acute lymphoblastic leukemia (ALL), occurring in about $20 \%$ to $30 \%$ of all cases [1-2]. The incidence increases with age, accounting for up to $50 \%$ of patients above the age of 50 [3]. Before the introduction of tyrosine kinase inhibitors (TKI), the outcome of the majority of patients with $\mathrm{Ph}$-positive $(\mathrm{Ph}+)$ ALL was poor [4-6]. Combining the first $\left(1^{\text {st }}\right)$ generation TKI imatinib with chemotherapy with or without allogeneic hematopoietic stem cell transplantation (HSCT) has substantially improved the survival of $\mathrm{Ph}+$ ALL patients [7-10], with longtime overall survival (OS) ranging from $40 \%-65 \%$, compared to the $20 \%-40 \%$ in pre-imatinib era. Therefore it has become the standard of care. The second $\left(2^{\text {nd }}\right)$-generation TKIs, for example dasatinib, is 300 -fold more active than imatinib in vitro [11-12], and has shown marked efficacy in relapsed patients or those refractory to imatinib [13-15], especially in those with imatinib-resistant BCR-ABL mutations. More recently, the $2^{\text {nd }}$-generation TKIs have been used as first-line treatment with promising results [16-19]. Thus we wonder whether the $2^{\text {nd }}$-generation TKIs could replace the $1^{\text {st }}$-generation TKI as the upfront treatment for $\mathrm{Ph}+$ ALL. However, up until now, to our knowledge, there were no randomized trials directly comparing the $1^{\text {st }}$ and $2^{\text {nd }}$-generation TKIs in treating newly diagnosed $\mathrm{Ph}+\mathrm{ALL}$ [20]. Literature review of prospective studies of each TKIs 
Table 1: Clinical characteristic of 77 patients with Ph+ ALL

\begin{tabular}{|c|c|c|c|c|}
\hline & Total & $1^{\text {st }}$-generation TKI & $2^{\text {nd }}$-generation TKIs & P-value \\
\hline Patients (N) & 77 & 45 & 32 & \\
\hline Median age (years) (range) & $30(13-59)$ & $28(13-59)$ & $32(14-59)$ & 0.135 \\
\hline Gender, male/female (ratio) & $52 / 25(2.1)$ & $28 / 17(1.6)$ & $24 / 8(3.0)$ & 0.238 \\
\hline WBC count $\left(\times 10^{9} / \mathrm{L}\right)$ & $61.7(0.7-517.0)$ & $77.5(0.7-352.0)$ & $40.2(1.0-517.0)$ & 0.812 \\
\hline EGIL classification: ALL/BAL & $67 / 10$ & $40 / 5$ & $27 / 5$ & 0.561 \\
\hline ACAs (yes/no) & $47 / 30$ & $25 / 20$ & $22 / 10$ & 0.242 \\
\hline BCR/ABL1- P190/P210 & $51 / 26$ & $34 / 11$ & $17 / 15$ & 0.040 \\
\hline $\begin{array}{l}\text { ABL1 gene mutations (yes/no) } \\
(\mathrm{n}=35)^{*}\end{array}$ & $29 / 6$ & $20 / 2$ & $9 / 4$ & 0.100 \\
\hline Allo-HSCT (yes/no) & $53 / 24$ & $34 / 11$ & $19 / 13$ & 0.131 \\
\hline
\end{tabular}

Abbreviations: TKI, tyrosine kinase inhibitor; WBC, white blood cell; EGIL, European Group for the immunological classification of leukemias; ACA, additional chromosomal abnormality; Allo-HSCT, allogeneic hematopoietic stem cell transplantation.

*35 patients were available for ABL1 mutation detection. Among the 6 patients with ABL1 gene mutations, no T315I mutation was found.

showed no evidence that the $2^{\text {nd }}$-generation TKIs provided better OS [9-10, 16-19, 21]. Furthermore, patients who were treated with dasatinib had higher incidence of pleural effusions and hemorrhage, and there was more concern of developing T315I mutation [16-17, 22-23]. Currently both imatinib and dasatinib are registered as the front-line treatment for $\mathrm{Ph}+\mathrm{ALL}$, and the other $2^{\text {nd }}$-generation TKIs are suggested as an alternative to those who failed the firstline treatment $[20,24]$. Whether the $2^{\text {nd }}$-generation TKIs could replace imatinib and provide better outcome when being used as the first-line treatment for $\mathrm{Ph}+\mathrm{ALL}$ need further clinical study. This single center study has focused on the efficacy comparing the $1^{\text {st }}$ and $2^{\text {nd }}$-generation TKIs in the front-line treatment of $\mathrm{Ph}+\mathrm{ALL}$.

\section{RESULTS}

\section{Characteristics of patients}

Of all the 109 newly diagnosed $\mathrm{Ph}+$ ALL patients, only 77 patients were given upfront treatment with TKIs and enrolled in this study. Patients were grouped based on the TKIs they received, first vs second generation: 45 on imatinib (43 at the dose of $400 \mathrm{mg}$ daily), 30 on dasatinib (20/30 at the dose of $100 \mathrm{mg}$ daily) and 2 on nilotinib. Fifty-three of 77 patients received allo-HSCT.

We had a male dominant patient population with male to female ratio 52 to 25 . The median age of onset was 30 (13-59), and the median peripheral WBC was $61.7(0.7-517.0) \times 10^{9} / \mathrm{L}$. Thirteen percent $(10$ out of 77 ) cases behaved as Biphenotypic Acute Leukemia (BAL) according to European Group for the Immunological Characterization of Leukemia (EGIL) classification [25].
Fifty one patients (66\%) harbored BCR-ABL1-p190 and $26(33.8 \%)$ carried BCR-ABL1-p210; 30 (39.0\%) had additional chromosomal abnormalities (ACAs), and $6(17.1 \%)$ presented with ABL1 mutations. The demographic characteristics were comparable between the groups treated with the $1^{\text {st }}$ - and with $2^{\text {nd }}$-generation TKIs, with exception of higher carrier of p190 in patients receiving the $1^{\text {st }}$-generation TKI. Details of patient characteristics were listed in Table 1.

\section{Early treatment responses}

After the first cycle of induction therapy, 56 (72.7\%) patients achieved CR, and 22 (28.6\%) had MMR. The numbers of patients having CR and MMR following two cycles of induction therapy increased to $65(84.4 \%)$ and 47 (61\%) respectively. Accumulatively there were 72 (93.5\%) patients having CR and $32(41.6 \%)$ being MRD negative prior to allo-HSCT. No statistic difference were observed in patients being treated with the $1^{\text {st }}$-generation TKI compared to those treated with the $2^{\text {nd }}$-generation TKIs, with respect to early response following induction therapy, total $\mathrm{CR} /$ MMR rates, median time to $\mathrm{CR} / \mathrm{MMR}$, and percentage of MRD status (Figure 1); Nor did we observe any difference in early relapse, defined as disease relapse prior to SCT (Table 2). We further performed univariate and multivariate analysis to identify risk factors, including gender, age of onset, WBC count, immunology, chromosome abnormalities, BCR/ABL1 subtype, ABL1 mutation, and TKI that patients received, which could potentially impact patients' early response. Both BCR-ABL1-p210 transcript and ABL1 mutations were the risk factors adversely affecting patients' early molecular response (Table 3 ). 
Table 2: The treatment responses of the patients with $\mathrm{Ph}+\mathrm{ALL}$

\begin{tabular}{lcccc}
\hline & Total & $\mathbf{1}^{\text {st }}$-generation TKI & $\mathbf{2}^{\text {nd }}$-generation TKI & P-value \\
\hline Patients (N) & 77 & 45 & 32 & \\
$1^{\text {st }}$ cycle CR rate (\%) & $56(72.7)$ & $32(75.0)$ & $24(71.1)$ & 0.706 \\
MMR rate after 1 $1^{\text {st }}$ induction & $22(28.6)$ & $15(33.3)$ & $7(21.5)$ & 0.273 \\
$2^{\text {nd }}$ cycle cumulative CR rate & $65(84.4)$ & $39(86.7)$ & $25(81.3)$ & 0.518 \\
Cumulative MMR rate after 2 ${ }^{\text {nd }}$ & $47(61.0)$ & $29(64.4)$ & $18(56.3)$ & 0.467 \\
chemotherapy & $72(93.5)$ & $43(95.6)$ & $29(90.6)$ & 0.387 \\
Total CR rate before SCT & $33.5(11-113))$ & $40(11-113)$ & $27(11-80)$ & 0.103 \\
Median time to CR (days) & $32(41.6)$ & $20(44.4)$ & $12(37.5)$ & 0.542 \\
MRD negative rate before SCT & $60(14-226)$ & $61(14-163)$ & $60(14-226)$ & 0.623 \\
Time to MRD negative (days) & $22 / 72(30.6)$ & $13 / 43(30.2)$ & $9 / 29(31.0)$ & 0.942 \\
Relapse before SCT & $135(22-450)$ & $114(22-450)$ & $201(22-310)$ & 0.471 \\
TTP before SCT (days) & $263(22-2134)$ & $247(22-2134)$ & $280(22-1094))$ & 0.890 \\
DFS (days) & $456(59-2327)$ & $478(71-2327)$ & $425(59-1221)$ & 0.264 \\
OS (days) & $20(26.0)$ & $12(26.7)$ & $8(25.0)$ & 0.869 \\
CNSL & $5 / 17(29.4)$ & $1 / 9(11.1)$ & $4 / 8(50.0)$ & 0.079 \\
T315 mutation/relapsed cases* &
\end{tabular}

Abbreviations: CR, complete remission; MMR, major molecular response; MRD, minimal residual disease; TTP, time to progress; DFS, disease free survival; OS, overall survival; CNSL, center nervous system leukemia.

*17 out of 33 relapsed patients were available for ABL1 gene mutation detection.
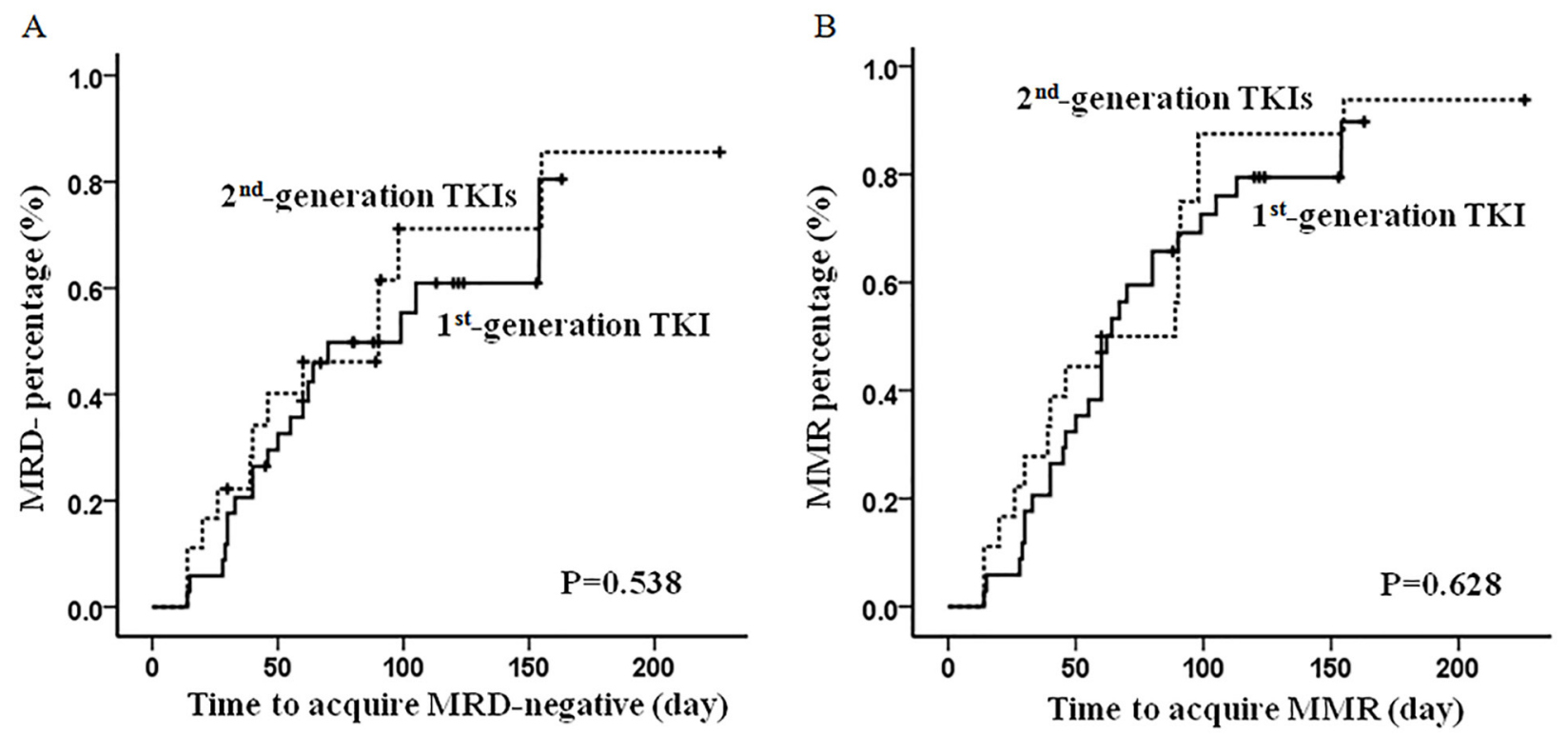

Figure 1: The median time to achieve MMR and MRD-negative. No significant difference in the median time to achieve MRDnegative (A) and MMR (B) were observed between the patients received the $1^{\text {st }}$ - and $2^{\text {nd }}$-generation TKIs as front-line treatment. 
Table 3: The adverse factors for early treatment response

\begin{tabular}{|c|c|c|c|c|c|c|c|c|c|}
\hline & \multicolumn{3}{|c|}{$1^{\text {st }}$ cycle-MMR } & \multicolumn{3}{|c|}{$2^{\text {nd }}$ cycle cumulate-MMR } & \multicolumn{3}{|c|}{ MRD-negative } \\
\hline & HR & $95 \% \mathrm{CI}$ & P value & HR & $95 \% \mathrm{CI}$ & P value & HR & $95 \% \mathrm{CI}$ & P value \\
\hline \multicolumn{10}{|l|}{ Univariate factors ${ }^{a}$} \\
\hline $\begin{array}{l}\text { Gender } \\
\text { (male vs. female) }\end{array}$ & 1.69 & $0.60-4.73$ & $0 . .319$ & 1.20 & $0.45-3.23$ & 0.712 & 0.96 & $0.37-2.49$ & 0.924 \\
\hline $\begin{array}{l}\text { Age } \\
(\geq 35 y \text { vs. }<35 y)\end{array}$ & 2.10 & $0.67-6.54$ & 0.200 & 1.24 & $0.47-3.24$ & 0.667 & 1.16 & $0.44-3.04$ & 0.763 \\
\hline $\begin{array}{l}\text { WBC }\left(\geq 1000 \times 10^{9} /\right. \\
\left.1 \text { vs. }<100 \times 10^{9} / 1\right)\end{array}$ & 1.66 & $0.58-4.71$ & 0.342 & 2.44 & $0.95-6.27$ & 0.064 & 1.22 & $0.48-3.08$ & 0.677 \\
\hline $\begin{array}{l}\text { EGIL classification } \\
\text { (BAL vs. ALL) }\end{array}$ & 4.11 & $0.49-34.56$ & 0.193 & 1.68 & $0.44-6.38$ & 0.446 & 0.68 & $0.18-2.56$ & 0.563 \\
\hline $\begin{array}{l}\text { ACA (with vs. } \\
\text { without) }\end{array}$ & 1.12 & $0.41-3.08$ & 0.825 & 0.74 & $0.29-1.89$ & 0.530 & 1.41 & $0.56-3.56$ & 0.468 \\
\hline $\begin{array}{l}\text { BCR/ABL1 } \\
\text { (P210 vs. P190) }\end{array}$ & 7.74 & $1.65-36.41$ & 0.010 & 2.55 & $0.97-6.74$ & 0.059 & 3.47 & $1.20-10.05$ & 0.022 \\
\hline $\begin{array}{l}\text { ABL1 gene } \\
\text { mutations } \\
\text { (yes vs. no) }\end{array}$ & $2.75 \mathrm{E} 8$ & $2.75 \mathrm{E} 8$ & $<0.001$ & $1.13 \mathrm{E} 8$ & $1.13 \mathrm{E} 8$ & $<0.001$ & 4.73E7 & 4.73E7 & $<0.001$ \\
\hline $\begin{array}{l}\text { The generation of } \\
\text { TKI }\left(2^{\text {nd }} \text { vs. } 1^{\text {st }}\right)\end{array}$ & 1.79 & $0.63-5.06$ & 0.276 & 1.41 & $0.56-3.56$ & 0.468 & 1.33 & $0.53-3.37$ & 0.543 \\
\hline \multicolumn{10}{|l|}{ Multivariate factors ${ }^{\mathrm{b}}$} \\
\hline $\begin{array}{l}\text { BCR/ABL1 (P210 } \\
\text { vs. P190) }\end{array}$ & 7.99 & $1.53-41.86$ & 0.014 & & & & 4.80 & $1.38-16.77$ & 0.014 \\
\hline $\begin{array}{l}\text { ABL1 gene } \\
\text { mutations } \\
\text { (yes vs. no) }\end{array}$ & $4.86 \mathrm{E} 7$ & $4.86 \mathrm{E} 7$ & $<0.001$ & $2.31 \mathrm{E} 8$ & $2.31 \mathrm{E} 8$ & $<0.001$ & $6.92 \mathrm{E} 7$ & $6.92 \mathrm{E} 7$ & $<0.001$ \\
\hline
\end{tabular}

Abbreviations: HR, hazard ratio; 95\%CI, 95\% confidence interval

${ }^{a}$ Factors with $\mathrm{P}<0.10$ in the univariate analyses were subjected to multivariate analysis afterwards.

${ }^{\mathrm{b}}$ Backward stepwise Cox proportional-hazard modeling was used in multivariate analysis of risk factors.

\section{DFS and OS}

With median follow-up of 456 (59-2327) days, 33 $(33 / 72,45.8 \%)$ patients relapsed and 22 relapsed prior to SCT. A total of 33 (33/77, 42.9\%) patients died: 25 from relapsed or refractory disease and 8 from treatment related events. Compared to patients receiving the $1^{\text {st }}$-generation TKI, we noted a trend toward better DFS in patients being treated with the $2^{\text {nd }}$-generation TKIs $(P=0.088)$, although this difference was not statistically significant. The OS was comparable between the two groups $(P=0.210)$ (Figure 2). As expected, patients undergoing allo-HSCT had much longer DFS ( $1615 \pm 144$ vs. $192 \pm 32$ days, $\mathrm{P}<0.001)$ and OS $(1463 \pm 147$ vs. $402 \pm 57$ days, $\mathrm{P}<0.001)$ than those without allo-HSCT. Interestingly, if patients underwent allo-HSCT, there was better survival in both DFS $(P=0.050)$ and OS $(P=0.048)$ when patients were given upfront therapy with the $2^{\text {nd }}$-generation TKIs compared to those on the $1^{\text {st }}$ - generation TKIs. We did not, however, note any difference in survival in non-allo-HSCT patients regardless of TKIs they received (Figure 3). The univariate and multivariate analysis further suggested that upfront treatment with the $2^{\text {nd }}$-generation TKIs could improve long term survival (Table 4).

\section{ABL1 gene mutations}

Six out of 35 (17.1\%) patients had ABL1 mutations at diagnosis. The outcomes of these patients were: one maintained CCR, one had refractory disease and could not attain $\mathrm{CR}$, and the rest four relapsed including two undergoing allo-HSCT (Table 5). Among 33 patients who relapsed, 17 were available for ABL1 mutation examination, and $7(7 / 17,41.2 \%)$ harbored mutant genes, including 5 with T315I mutation (Table 5). According to the previous reports $[16,18,23], \mathrm{T} 315 \mathrm{I}$ mutation could be 
induced or positively selected by the $2^{\text {nd }}$-generation TKIs, and mainly contributed to leukemia relapse, we further did subgroup analysis of the frequency of T315I mutation in the patients relapsed on the $1^{\text {st }}$ vs. $2^{\text {nd }}$-generation TKIs, and found that the incidence in the $2^{\text {nd }}$-generation TKI group was apparently, though not statistically, might be due to small case number, higher than that in the $1^{\text {st }}$-generation TKI group ( $4 / 8$ vs. $1 / 9, \mathrm{P}=0.079$ ) (Table 2 ).

\section{Toxicity}

All patients tolerated TKIs well, with exception of 3 patients from the $2^{\text {nd }}$-generation TKI group and 5 from the $1^{\text {st }}$-generation TKI group whose treatment were temporally on hold because of severe bone marrow suppression. One patient with dasatinib had subcutaneous hemorrhage not attributable to platelet count or coagulation status. Pleural effusion was observed in patients receiving both the $1^{\text {st }}(3$ out of 45 patients) and $2^{\text {nd }}$ ( 5 out of 32 patients) generation TKIs $(\mathrm{P}>0.05)$

\section{DISCUSSION}

TKI combined with multiagent chemotherapy has been well accepted as the front-line treatment of $\mathrm{Ph}+$ ALL, and the patients under 65 are recommended to receive allo-HSCT if a matched donor is available [20, 24]. In this study, we confirmed the survival advantage of consolidation with allo-HSCT in $\mathrm{Ph}+\mathrm{ALL}$ patients, even though TKIs had been continuously used through induction and consolidation. More importantly, our study indicated that the survival benefit from upfront treatment with the $2^{\text {nd }}$-generation TKI only occurred in patients who received allo-HSCT but not in those who were treated with chemotherapy alone.

In the past the significant survival advantage of incorporation of imatinib into the treatment of $\mathrm{Ph}+$ ALL patients has established imatinib as the standard of care [7-10]. However, there is concern of acquired or intrinsic resistance to imatinib, mainly due to BCRABL mutation or over-expression and the activation of Scr kinase pathway, leading to treatment failure [26-28]. The $2^{\text {nd }}$-generation inhibitors, in particular dasatinib, were reported to be capable of overcoming such resistance and have higher antileukemic efficacy. It has been widely used to treat patients who are refractory to or untolerate to imatinib, and has shown promising result [13-15]. More recently, the $2^{\text {nd }}$-generation TKIs have been used as the first-line therapy in newly diagnosed $\mathrm{Ph}+\mathrm{ALL}$ patients. A report of 53 adults with newly diagnosed $\mathrm{Ph}+\mathrm{ALL}$ received combination of dasatinib with prednisone for induction and free post-induction therapy showed that all evaluable patients attained complete hematologic remission (CHR), and the 20-month OS and DFS were $69.2 \%$ and $51.1 \%$, respectively [16]. A phase 2 study [17] of dasatinib with hyper-CVAD for the front-line treatment was conducted in 35 patients with newly diagnosed $\mathrm{Ph}+$ ALL and reported a CR rate of $94 \%$ and the estimated 2 -year OS rate of $64 \%$. The recent follow-up update reported on 72 patients and showed a CR rate of $96 \%$, with a median DFS and OS of 31 and 47 months [18]. Thus, as imatinib, dasatinib has been recommended as the front-line treatment for newly diagnosed Ph+ ALL [20, 24]. These prospective non-randomized controlled studies, however, showed no evidence that the dasatinib provides survival benefit to $\mathrm{Ph}+\mathrm{ALL}$ patients when compared with
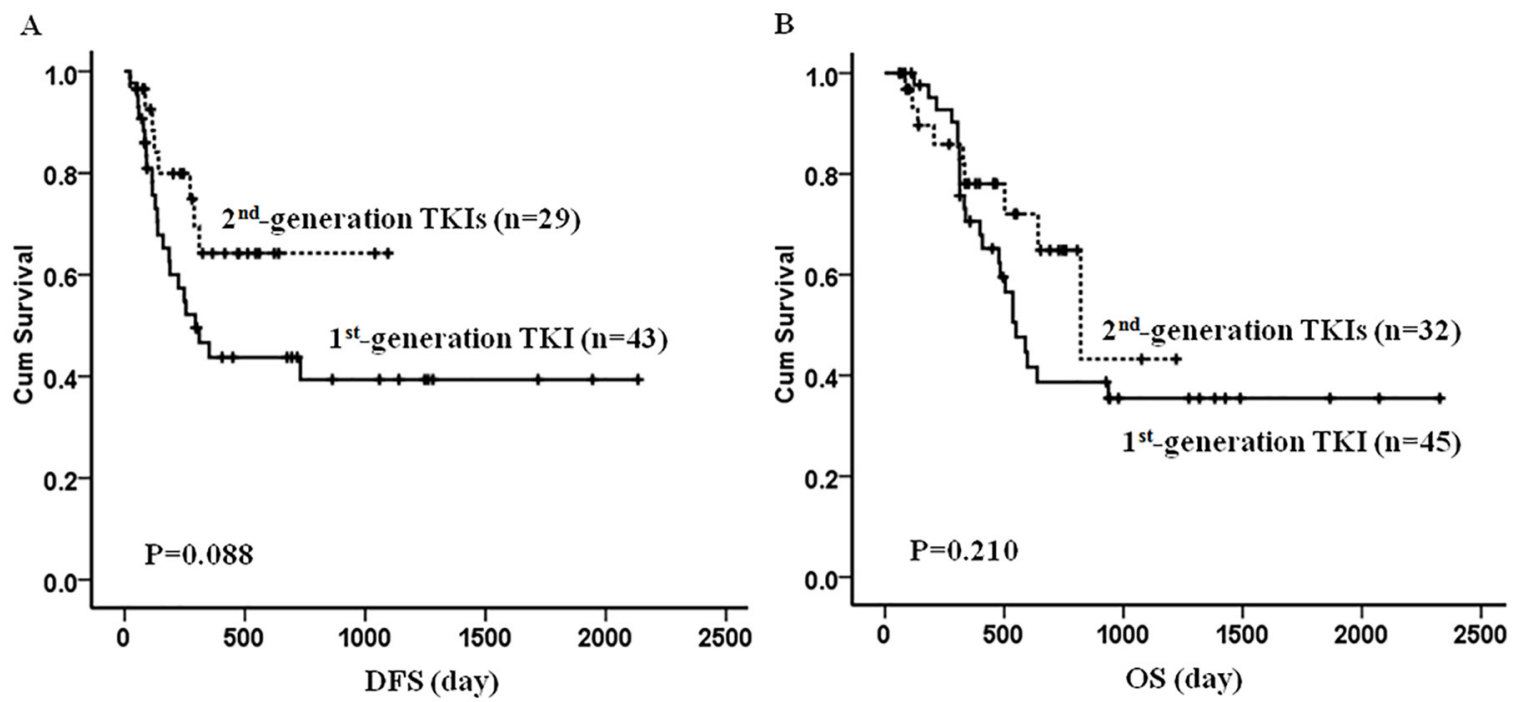

Figure 2: The DFS and OS in the patients front-line treated with the $\mathbf{1}^{\text {st }}$ and $\mathbf{2}^{\text {nd }}$-generation TKIs. An apparently, though not significantly, better DFS was observed in patients being treated with the $2^{\text {nd }}$-generation TKIs compared with that in the $1^{\text {st }}$-generation TKI group (A, $P=0.088)$. The OS was comparable between the two groups $(\mathbf{B}, P=0.210)$. 
imatinib. Only some patients in those trials received alloHSCT. Up until now, there is no study directly comparing the treatment of the two generations TKIs in patients undergoing allo-HSCT.

In our study, among the 53 patients consolidated with allo-HSCT, 34 were front-line treated with imatinib, 19 received the $2^{\text {nd }}$-generation TKIs, mainly dasatinib. With median follow-up of 456 (59-2327) days, there was no significant difference in DFS and OS between the two groups. Subgroup analysis, however, showed benefit in DFS $(p=0.05)$ and OS $(p=0.048)$ in patients treated with the $2^{\text {nd }}$-generation TKIs only when they underwent alloHSCT. The benefit from TIKs disappeared if patients were treated with chemotherapy only. It is well known that the frequency of T315I mutation and/or multiple ABL1 mutations are higher in patients with long-term TKIs treatment [7, 16-17, 24, 28], which is thought as the major reason for leukemia relapse. Therefore TKIs are only considered as a complement to chemotherapy, serving as a bridge to allo-HSCT. To this date, allo-SCT is still the best treatment option for long term survival in younger and fit $\mathrm{Ph}+\mathrm{ALL}$ patients [20, 23-24]. Our result also indicated that among the patients with continuous TKI treatment, those consolidated with allo-HSCT after CR1 had better DFS and OS.

TKI-resistant mutations have been detected in a variable proportion of TKI-naive $\mathrm{Ph}+\mathrm{ALL}$ cases [23, 29-30]. Since dasatinib is a dual Src and Abl kinase inhibitor that binds to both active and inactive moieties of the BCR-ABL1 protein and is approximately 300 times more potent against the kinase [11-12], it should be more effective as first-line when incorporated into the treatment. The efficacy of dasatinib was confirmed in the treatment for Chronic Myelogenous Leukemia (CML) [31], although the clinical evidence in $\mathrm{Ph}+\mathrm{ALL}$ patients were lacking. In our study, we did not observe significant
A

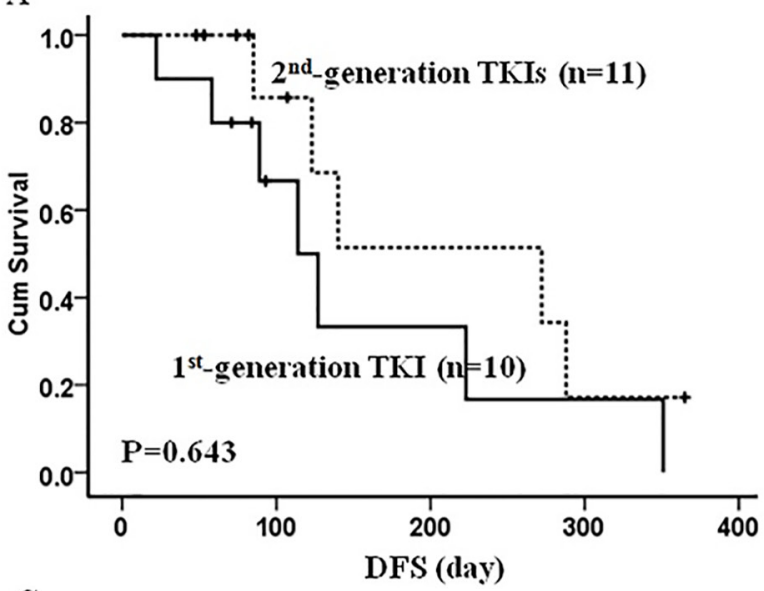

C

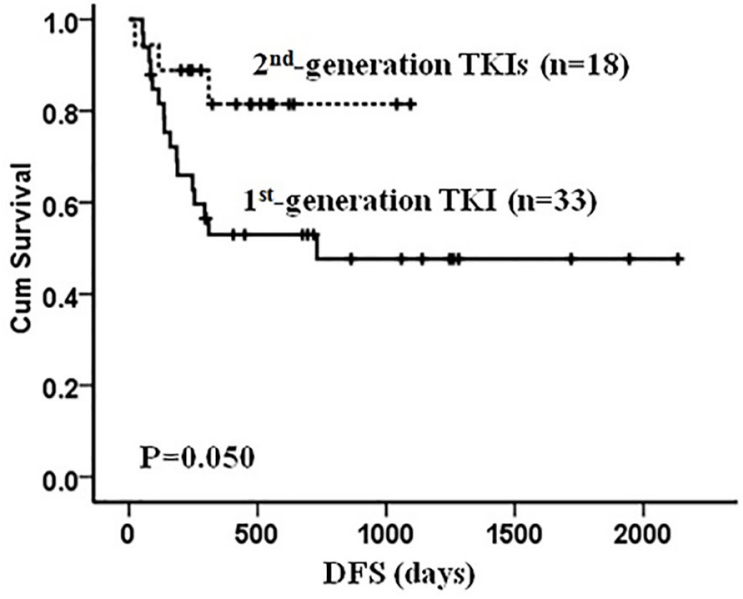

B

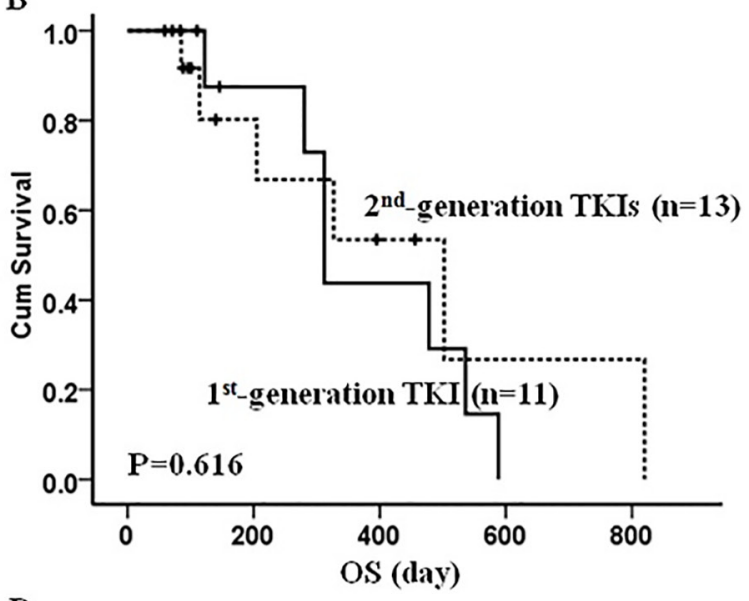

D

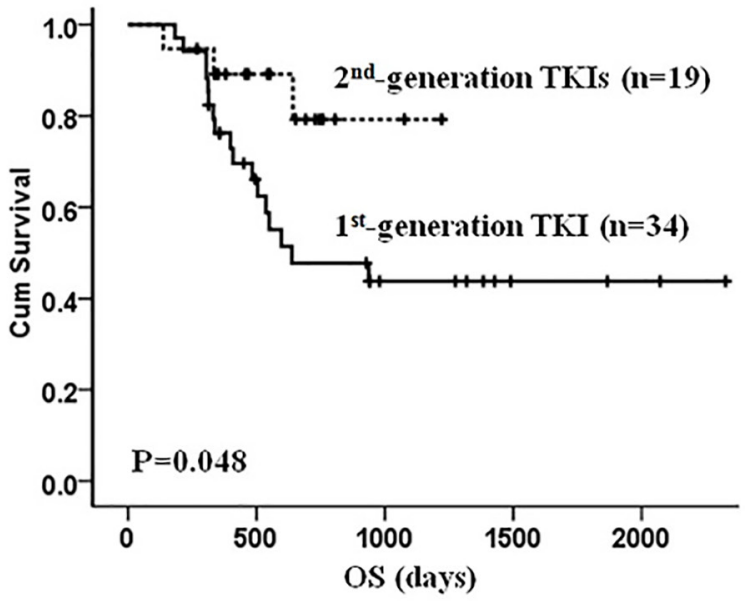

Figure 3: The DFS and OS in the patients front-line treated with the $1^{\text {st }}$ and $2^{\text {nd }}$-generation TKIs combining with or without allo-HSCT. Figure (A, B) showed that among the patients without receiving allo-HSCT, there was no obvious difference in the DFS between the two groups (DFS, $\mathrm{P}=0.643$; OS, $\mathrm{P}=0.616$ ). Figure $(\mathbf{C}, \mathbf{D})$ showed that among the patients receiving allo-HSCT, both DSF and OS were significantly better in the $2^{\text {nd }}$-generation TKIs group compared with that in the $1^{\text {st }}$-generation TKI group (DFS, $\mathrm{P}=0.050$; OS, $\mathrm{P}=0.048)$. 
Table 4: The risk factors for DFS and OS in ph-ALL

\begin{tabular}{|c|c|c|c|c|c|c|}
\hline & \multicolumn{3}{|c|}{ DFS } & \multicolumn{3}{|c|}{ OS } \\
\hline & HR & $95 \% \mathrm{CI}$ & $P$ value & HR & $95 \%$ CI & P value \\
\hline \multicolumn{7}{|l|}{ Univariate factors ${ }^{a}$} \\
\hline Gender (male vs. female) & 1.99 & $0.76-5.25$ & 0.163 & 0.91 & $0.35-2.39$ & 0.851 \\
\hline Age $(\geq 35 y$ vs. $<35 y)$ & 1.30 & $0.58-2.92$ & 0.523 & 2.50 & $1.01-6.18$ & 0.048 \\
\hline WBC $\left(\geq 1000 \times 10^{9} / 1\right.$ vs. $\left.<100 \times 10^{9} / 1\right)$ & 1.17 & $0.51-2.67$ & 0.712 & 1.00 & $1.00-1.01$ & 0.279 \\
\hline EGIL classification ( BAL vs. ALL) & 1.48 & $0.43-5.09$ & 0.538 & 2.80 & $0.72-10.83$ & 0.136 \\
\hline ACA (with vs. without) & 0.81 & $0.37-1.78$ & 0.598 & 1.20 & $0.50-2.90$ & 0.687 \\
\hline BCR/ABL1 (P210 vs. P190) & 0.65 & $0.24-1.76$ & 0.394 & 0.60 & $0.21-1.75$ & 0.352 \\
\hline ABL1 gene mutations (yes vs. no) & 0.82 & $0.27-2.48$ & 0.727 & 0.82 & $0.31-2.20$ & 0.697 \\
\hline The generation of TKI ( $2^{\text {nd }}$ vs. $\left.1^{\text {st }}\right)$ & 0.34 & $0.12-0.92$ & 0.034 & 0.42 & $0.42-3.56$ & 0.069 \\
\hline Allo-HSCT (with vs. without) & 0.31 & $0.13-0.75$ & 0.010 & 0.38 & $0.16-0.93$ & 0.034 \\
\hline \multicolumn{7}{|l|}{ Multivariate factors $^{\mathrm{c}}$} \\
\hline The generation of TKI $\left(2^{\text {nd }}\right.$ vs. $\left.1^{\text {st }}\right)$ & 0.40 & $0.18-0.91$ & 0.030 & 0.41 & $0.18-0.93$ & 0.033 \\
\hline Allo-HSCT (with vs. without) & 0.23 & $0.10-0.49$ & $<0.001$ & 0.24 & $0.11-0.51$ & $<0.001$ \\
\hline
\end{tabular}

Table 5: ABL1 gene mutations at diagnosis and relapse in ph+ ALL

\begin{tabular}{lcccc}
\hline Patients & $\begin{array}{c}\text { TKI for front-line } \\
\text { treatment }\end{array}$ & $\begin{array}{c}\text { ABL1 mutations at } \\
\text { diagnosis }\end{array}$ & Status & ABL1 mutations at relapse \\
\hline Case 1 & dasatinib & F317L & Relapse & No mutation \\
Case 2 & dasatinib & L248V & Relapse & Y253H, E459K \\
Case 3 & imatinib & L523P, E505K & CCR & \\
Case 4 & nilotinib & No mutation & Relapse & T315I \\
Case 5 & imatinib & F317L & NR & \\
Case 6 & dasatinib & No mutation & Relapse & T315I \\
Case 7 & nilotinib & Y253 & Relapse & Y253, E255K \\
Case 8 & dasatinib & c.944C>T/p & Relapse & T315I \\
Case 9 & dasatinib & No mutation & Relapse & T315I \\
Case 10 & imatinib & No mutation & Relapse & T315I \\
\hline
\end{tabular}

difference in early response between the two generation TKIs groups; however, the $2^{\text {nd }}$-generation TKIs seemed to reverse the adverse effect of BCR-ABL1-p210 and ABL1 mutation on early molecular response. The presence of TKI resistant mutations, in particular T315I mutation, increased with long term exposure to TKIs, which could explain comparable OS among two groups. If allo-HSCT was available following CR1, the development of TKIresistance sub-clones were successfully suppressed, and OS was improved.
We confirmed previous clinical trials [13-18] that the $2^{\text {nd }}$-generation TKIs were well tolerated. The main concern is the development of ABL1 mutation, especially T315I mutation. There was $33 \%$ to $70 \%$ of patients having T315I mutation when relapsed on upfront dasatinib [16$17]$; and $65 \%$ of patients acquired the T315I mutation when they were rescued with dasatinib after progressed on imatinib [23]. The development of T315I was much higher than that in imatinib failure cases $[9,23]$. Similarly, in our study T315I mutation occurred at apparently 
higher rate in the patients relapsed on the $2^{\text {nd }}$-generation TKIs. Therefore, we need to pay more attention to T315I mutation in the cases failure on the $2^{\text {nd }}$-generation TKI.

To sum up, front-line treatment of newly diagnosed $\mathrm{Ph}+\mathrm{ALL}$ patients with the $2^{\text {nd }}$-generation TKIs, especially dasatinib, is as effective and safe as imatinib; when alloHSCT is incorporated as consolidation therapy following CR1, survival benefit was observed with the $2^{\text {nd }}$-generation TKIs. T315I occurred at higher rate when patients relapsed on the $2^{\text {nd }}$-generation TKIs and deserved further attention. Finally we advise a multicenter prospective control clinical trial to confirm the conclusion.

\section{MATERIALS AND METHODS}

\section{Patients}

One hundred and nine patients were diagnosed as $\mathrm{Ph}+\mathrm{ALL}$, based on the World Health Organization (WHO) 2008 classification, from January, 2010 to January, 2016 in department of Hematology, Nanfang hospital. Seventy seven were given upfront treatment with TKIs combined with chemotherapy with or without allo-HSCT. Informed consents were signed and obtained from all patients or guardians in accordance with the regulations of Nanfang hospital, Southern Medical college of Medicine Institutional Review Boards in agreement with the 'Declaration of Helsinki'.

\section{Treatments and study plan}

TIKs, at the dose of imatinib 400 or $600 \mathrm{mg}$, dasatinib 100 or $140 \mathrm{mg}$, or nilotinib $800 \mathrm{mg}$, by mouth daily, were started at the time of diagnosis and continued throughout the whole treatment. The TIKs were temporarily discontinued when severe bone marrow suppression or severe non-hematologic toxicities were developed. Patients were advised to switch to another TKIs in the setting of relapse. The choice of TKIs was based on patients' personal preference and economic situations after fully discussing with their physicians. The VI(D)LP (vincristine, daunorubicin or idarubicin, L-asparagines, and prednisone) was given for 1-2 cycles as induction regimen, and this was followed by hyper-CVAD-A (cyclophosphamide, vincristine, daunorubicin, and dexamethasone) alternating with hyper-CVAD-B (high-dose methotrexate and cytarabine) as the consolidation regimen for 2-4 cycles, if CR was obtained; Allo-HSCT were offered if appropriate donors were available. If donors were not available, consolidation regimens with hyper-CVAD-A \pm L-asp/B combined with a TKI were continued to $6-8$ cycles, and postconsolidation maintenance therapy with a TKI combined with dexamethasone (MTX)/6-Mercaptopurine (6-MP) lasted for 2-3 years. For patients who underwent allo-HSCT, to prevent relapse, reduction of immunosuppressive therapy and prophylactic donor lymphocyte infusion (DLI) were routinely initiated 60-90 days post-transplantation. The use of post-transplant TKIs depended on the MRD status. And TKIs were resumed when BCR/ABL1 transcript increased by one log. All patients received central nervous system leukemia (CNSL) prophylaxis.

If patients relapsed before transplantation, they were suggested to stop and change to another TIKs depending on ABL1 gene mutation. Rescue regimens containing high dose MTX, cyclophosphamide (CTX) or L-Asparaginasum (L-Asp), such as VICLP (VILP plus CTX), CAM (CTX, cytarabine, 6-MP), or high dose MTX plus L-Asp, were given, and allo-HSCT was initiated immediately if a donor was available. If relapse occurred after transplantation, immunosuppression for GVHD was reduced or stopped. DLI was considered if available, and TKIs which were effective in their previous treatment were restarted. If there was concern of leukemia, multiagent chemotherapy could be initiated.

\section{Diagnosis of $\mathrm{Ph}+\mathrm{ALL}$ and MRD monitoring}

Diagnosis of $\mathrm{Ph}+\mathrm{ALL}$ was made according to WHO 2008 classification by fluorescence in situ hybridization analysis with positive $B C R-A B L 1$ and/or standard karyotype $\mathrm{t}(9 ; 22)(\mathrm{q} 34 ; \mathrm{q} 11)$. The $B C R-A B L 1$ fusion transcript, p190 and p210, were detected by using real-time quantitative polymerase chain reaction (RTQPCR) (Qiagen, Hilden, Germany) standardized methods with international scale [32]. The MRD, presenting as BCR-ABL1/ABL ratio, detected by RTQ-PCR, was monitored after induction therapy and every consolidation chemotherapy, then at 3-month intervals for the first 2 years of follow up, and at relapse. Major molecular response (MMR) was defined as a BCR-ABL1/ABL ratio of $0.05 \%$ in the bone marrow, and molecular CR was defined by the absence of detectable MRD with a sensitivity of at least $0.001 \%$ [33].

\section{ABL1 gene mutations analysis}

The samples obtained for RTQ-PCR were also analyzed for the BCR-ABL KD mutation by direct sequencing. Total RNA was extracted from mononuclear cells from the patients' prophase and relapse samples by TRIzol (Invitrogen), and cDNA was synthesized by reverse transcriptase. Briefly, nested PCR was applied to amplify the complementary DNA region encoding kinase domain of BCR-ABL. All primers were based on the report by Branford et al [34]. Scanning of the ABL KD (amino acids 219-506) for the presence of mutations was sequenced by Sanger [35]. The sample nucleotide sequences were compared to the GenBank accession no. X16416.

\section{Statistical analysis}

SPSS 17.0 software (SPSS Inc., Chicago, IL, USA) was used to evaluate the statistical difference of categorical 
variables between patient groups with the Pearson Chisquare analysis and Fisher exact test. DFS was calculated from the date of CR to the first relapse or the last followup. OS was calculated from the date of diagnosis to the death or the last follow-up. The Kaplan-Meier method and Log rank tests were performed to evaluate DFS and OS between the groups, and a $\mathrm{P}$ value of less than 0.05 was considered statistically significant.

\section{Abbreviations}

TKI, tyrosine kinase inhibitor; ALL, acute lymphoblastic leukemia; allo-HSCT, allogeneic hematopoietic stem cell transplantation; MRD, minimal residual disease; $\mathrm{CR}$, complete remission; $\mathrm{MMR}$, major molecular response; DFS, disease-free survival; OS, overall survival; ACA, additional chromosomal abnormality; HR, hazard ratio; 95\% CI, 95\% confidence interval; RTQ-PCR, real-time quantitative polymerase chain reaction.

\section{Author contributions}

Dan $\mathrm{Xu}$ and Guopan $\mathrm{Yu}$ conceptionized and designed the study, collected and analyzed data, and drafted the paper. Changxin Yin performed gene mutation sequencing. Fang Chen followed-up and analyzed patient data. Guopan Yu and Fang Chen contributed equally to this work. Qifa Liu, Jing Sun, Li Xuan, Zhiping Fan, Qiang Wang, Xiaoli Liu and Qianli Jiang collected patients' data.

\section{CONFLICTS OF INTEREST}

There is no conflicts of interest.

\section{FUNDING}

The present study was funded by the National Natural Science Foundation of China (grant no. 81500138), the clinical research initiative of Southern Medical University (grant no. LC2016YM006), and the President Funding of Nanfang Hospital (grant no. 2015C025).

\section{REFERENCES}

1. Secker-Walker LM, Craig JM, Hawkins JM, Hoffbrand AV. Philadelphia positive acute lymphoblastic leukemia in adults: age distribution, BCR breakpoint and prognostic significance. Leukemia. 1991; 5: 196-199.

2. Burmeister T, Schwartz S, Bartram CR, Gokbuget N, Hoelzer D, Thiel E. Patients' age and BCR-ABL frequency in adult B-precursor ALL: a retrospective analysis from the GMALL study group. Blood. 2008; 112: 918-919.

3. Larson RA. Management of acute lymphoblastic leukemia in older patients. Semin Hematol. 2006; 43: 126-133.
4. Takeuchi J, Kyo T, Naito K, Sao H, Takahashi M, Miyawaki S, Kuriyama K, Ohtake S, Yagasaki F, Murakami H, Asou $\mathrm{N}$, Ino $\mathrm{T}$, Okamoto $\mathrm{T}$, et al. Induction therapy by frequent administration of doxorubicin with four other drugs, followed by intensive consolidation and maintenance therapy for adult acute lymphoblastic leukemia: the JALSGALL93 study. Leukemia. 2002; 16: 1259-1266.

5. Moorman AV, Harrison CJ, Buck GA, Richards SM, Secker-Walker LM, Martineau M, Vance GH, Cherry AM, Higgins RR, Fielding AK, Foroni L, Paietta E, Tallman MS, et al; Adult Leukaemia Working Party, Medical Research Council/National Cancer Research Institute. Karyotype is an independent prognostic factor in adult acute lymphoblastic leukemia (ALL): analysis of cytogenetic data from patients treated on the Medical Research Council (MRC) UKALLXII/Eastern Cooperative Oncology Group (ECOG) 2993 trial. Blood. 2007; 109: 3189-3197.

6. Pullarkat V, Slovak ML, Kopecky KJ, Forman SJ, Appelbaum FR. Impact of cytogenetics on the outcome of adult acute lymphoblastic leukemia: results of Southwest Oncology Group 9400 study. Blood. 2008; 111: 2563-2572.

7. Ottmann OG, Druker BJ, Sawyers CL, Goldman JM, Reiffers J, Silver RT, Tura S, Fischer T, Deininger MW, Schiffer CA, Baccarani M, Gratwohl A, Hochhaus A, et al. A phase 2 study of imatinib in patients with relapsed or refractory Philadelphia chromosome-positive acute lymphoid leukemias. Blood. 2002; 100: 1965-1971.

8. Lee KH, Lee JH, Choi SJ, Lee JH, Seol M, Lee YS, Kim WK, Lee JS, Seo EJ, Jang S, Park CJ, Chi HS. Clinical effect of imatinib added to intensive combination chemotherapy for newly diagnosed Philadelphia chromosome-positive acute lymphoblastic leukemia. Leukemia. 2005; 19: 1509-1516.

9. Bassan R, Rossi G, Pogliani EM, Di Bona E, Angelucci E, Cavattoni I, Lambertenghi-Deliliers G, Mannelli F, Levis A, Ciceri F, Mattei D, Borlenghi E, Terruzzi E, et al. Chemotherapy-phased imatinib pulses improve long-term outcome of adult patients with philadelphia chromosomepositive acute lymphoblastic leukemia: Northern Italy Leukemia Group Protocol 09/00. J Clin Oncol. 2010; 28: 3644-3652.

10. Fielding AK, Foroni L, Gerrard G, Foroni L, Gerrard G, Litzow MR, Lazarus H, Luger SM, Marks DI, McMillan AK, Moorman AV, Patel B, Paietta E, et al. UKALLXII/ ECOG2993: addition of imatinib to a standard treatment regimen enhances long-term outcomes in Philadelphia positive acute lymphoblastic leukemia. Blood. 2014; 123: 843-850.

11. O'Hare T, Walters DK, Stoffregen EP, Jia T, Manley PW, Mestan J, Cowan-Jacob SW, Lee FY, Heinrich MC, Deininger MW, Druker BJ. in vitro activity of Bcr-Abl inhibitors AMN107 and BMS-354825 against clinically relevant imatinibresistant Abl kinase domain mutants. Cancer Res. 2005; 65: 4500-4505. 
12. Luo FR, Yang Z, Camuso A, Smykla R, McGlinchey K, Fager K, Flefleh C, Castaneda S, Inigo I, Kan D, Wen ML, Kramer R, Blackwood-Chirchir A, et al. Dasatinib (BMS-354825) pharmacokinetics and pharmacodynamic biomarkers in animal models predict optimal clinical exposure. Clin Cancer Res. 2006; 12: 7180-7186.

13. Talpaz M, Shah NP, Kantarjian H, Donato N, Nicoll J, Paquette R, Cortes J, O’Brien S, Nicaise C, Bleickardt E, Blackwood-Chirchir MA, Iyer V, Chen TT, et al. Dasatinib in imatinibresistant Philadelphia chromosome-positive leukemias. N Engl J Med. 2006; 354: 2531-2541.

14. Ottmann O, Dombret H, Martinelli G, Simonsson B, Guilhot F, Larson RA, Rege-Cambrin G, Radich J, Hochhaus A, Apanovitch AM, Gollerkeri A, Coutre S. Dasatinib induces rapid hematologic and cytogenetic responses in adult patients with Philadelphia chromosomepositive acute lymphoblastic leukemia with resistance or intolerance to imatinib: interim results of a Phase II study. Blood. 2007; 110: 2309-2315.

15. Shah NP, Kantarjian HM, Kim DW, Réa D, DorlhiacLlacer PE, Milone JH, Vela-Ojeda J, Silver RT, Khoury HJ, Charbonnier A, Khoroshko N, Paquette RL, Deininger M, et al. Intermittent target inhibition with dasatinib $100 \mathrm{mg}$ once daily preserves efficacy and improves tolerability in imatinib-resistant and -intolerant chronic-phase chronic myeloid leukemia. J Clin Oncol. 2008; 26: 3204-3212.

16. Foa R, Vitale A, Vignetti M, Meloni G, Guarini A, De Propris MS, Elia L, Paoloni F, Fazi P, Cimino G, Nobile F, Ferrara F, Castagnola C, et al; GIMEMA Acute Leukemia Working Party. Dasatinib as first-line treatment for adult patients with Philadelphia chromosome-positive acute lymphoblastic leukemia. Blood. 2011; 118: 6521-6528.

17. Ravandi F, O'Brien S, Thomas D, Faderl S, Jones D, Garris R, Dara S, Jorgensen J, Kebriaei P, Champlin R, Borthakur G, Burger J, Ferrajoli A, et al. First report of phase 2 study of dasatinib with hyper-CVAD for the frontline treatment of patients with Philadelphia chromosome-positive $(\mathrm{Ph}+)$ acute lymphoblastic leukemia. Blood. 2010; 116: 2070-2077.

18. Ravandi F, O'Brien SM, Cortes JE, Thomas DM, Garris R, Faderl S, Burger JA, Rytting ME, Ferrajoli A, Wierda WG, Verstovsek S, Champlin R, Kebriaei P, et al. Long-term follow-up of a phase 2 study of chemotherapy plus dasatinib for the initial treatment of patients with Philadelphia chromosome-positive acute lymphoblastic leukemia. Cancer. 2015; 121: 4158-4164.

19. Sasaki K, Jabbour EJ, Ravandi F, Short NJ, Thomas DA, Garcia-Manero G, Daver NG, Kadia TM, Konopleva MY, Jain N, Issa GC, Jeanis V, Moore HG, et al. HyperCVAD plus ponatinib versus hyper-CVAD plus dasatinib as frontline therapy for patients with Philadelphia chromosome-positive acute lymphoblastic leukemia: A propensity scoreanalysis. Cancer. 2016; 122: 3650-3656.
20. Malagola M, Papayannidis C, Baccarani M. Tyrosine kinase inhibitors in $\mathrm{Ph}+$ acute lymphoblastic leukaemia: facts and perspectives. Ann Hematol. 2016; 95: 681-693.

21. Chalandon Y, Thomas X, Hayette S, Cayuela JM, Abbal C, Huguet F, Raffoux E, Leguay T, Rousselot P, Lepretre S, Escoffre-Barbe M, Maury S, Berthon C, et al; Group for Research on Adult Acute Lymphoblastic Leukemia (GRAALL). Randomized study of reduced-intensity chemotherapy combined with imatinib in adults with Ph-positive acute lymphoblastic leukemia. Blood. 2015; 125: 3711-3719.

22. Brixey AG, Light RW. Pleural effusions due to dasatinib. Curr Opin Pulm Med. 2010; 16: 351-356.

23. Soverini S, De Benedittis C, Papayannidis C, Paolini S, Venturi C, Iacobucci I, Luppi M, Bresciani P, Salvucci M, Russo D, Sica S, Orlandi E, Intermesoli T, et al. Drug resistance and $\mathrm{BCR}-\mathrm{ABL}$ kinase domain mutations in Philadelphia chromosome-positive acute lymphoblastic leukemia from the imatinib to the second-generation tyrosine kinase inhibitor era: The main changes are in the type of mutations, but not in the frequency of mutation involvement. Cancer. 2014; 120: 1002-1009.

24. Acute Lymphoblastic Leukemia, Version 2.2016, NCCN Clinical Practice Guidelines in Oncology. https://www. nccn.org.

25. Bene MC, Castoldi G, Knapp W, Ludwig WD, Matutes E, Orfao A, van't Veer MB. Proposals for the immunological classification of acute leukemias. European Group for the Immunological Characterization of Leukemias (EGIL). Leukemia. 1995; 9: 1783-1786.

26. Branford S, Rudzki Z, Walsh S, Grigg A, Arthur C, Taylor K, Herrmann R, Lynch KP, Hughes TP. High frequency of point mutations clustered within the adenosine triphosphatebinding region of $\mathrm{BCR} / \mathrm{ABL}$ in patients with chronic myeloid leukemia or $\mathrm{Ph}$-positive acute lymphoblastic leukemia who develop imatinib (STI571) resistance. Blood. 2002; 99: 3472-3475.

27. Jones D, Thomas D, Yin CC, O'Brien S, Cortes JE, Jabbour E, Breeden M, Giles FJ, Zhao W, Kantarjian HM. Kinase domain point mutations in Philadelphia chromosomepositive acute lymphoblastic leukemia emerge after therapy with BCR-ABL kinase inhibitors. Cancer. 2008; 113: 985-994.

28. Shah NP, Nicoll JM, Nagar B, Gorre ME, Paquette RL, Kuriyan J, Sawyers CL. Multiple BCRABL kinase domain mutations confer polyclonal resistance to the tyrosine kinase inhibitor imatinib (STI571) in chronic phase and blast crisis chronic myeloid leukemia. Cancer Cell. 2002; 2: 117-125.

29. Pfeifer H, Lange T, Wystub S, Wassmann B, Maier J, Binckebanck A, Giagounidis A, Stelljes M, Schmalzing M, Dührsen U, Wunderle L, Serve H, Brück P, et al. Prevalence and dynamics of bcr-abl kinase domain mutations during imatinib treatment differ in patients with newly diagnosed 
and recurrent bcr-abl positive acute lymphoblastic leukemia. Leukemia. 2012; 26: 1475-1481.

30. Soverini S, Vitale A, Poerio A, Gnani A, Colarossi S, Iacobucci I, Cimino G, Elia L, Lonetti A, Vignetti M, Paolini S, Meloni G, di Maio V, et al. Philadelphia-positive acute lymphoblastic leukemia patients already harbor BCRABL kinase domain mutations at low levels at the time of diagnosis. Haematologica. 2011; 96: 552-557.

31. Hochhaus A, Kantarjian H. The development of dasatinib as a treatment for chronic myeloid leukemia (CML): from initial studies to application in newly diagnosed patients. J Cancer Res Clin Oncol. 2013; 139: 1971-1984.

32. Luthra R, Sanchez-Vega B, Medeiros LJ. TaqMan RT-PCR assay coupled with capillary electrophoresis for quantification and identification of bcr-abl transcript type. Mod Pathol. 2004; 17: 96-103.

33. Jabbour E, Kantarjian H, Jones D, Talpaz M, Bekele N, O'Brien S, Zhou X, Luthra R, Garcia-Manero G, Giles F, Rios MB, Verstovsek S, Cortes J. Frequency and clinical significance of BCR-ABL mutations in patients with chronic myeloid leukemia treated with imatinib mesylate. Leukemia. 2006; 20:1767-1773.

34. Branford S, Rudzki Z, Parkinson I, Grigg A, Taylor K, Seymour JF, Durrant S, Browett P, Schwarer AP, Arthur C, Catalano J, Leahy MF, Filshie R, et al. Real-time quantitative PCR analysis can be used as a primary screen to identify patients with CML treated with imatinib who have BCR-ABL kinase domain mutations. Blood. 2004; 104: 2926-2932.

35. Soverini S, Colarossi S, Gnani A, Rosti G, Castagnetti F, Poerio A, Iacobucci I, Amabile M, Abruzzese E, Orlandi E, Radaelli F, Ciccone F, Tiribelli M, et al; GIMEMA Working Party on Chronic Myeloid Leukemia. Contribution of ABL kinase domain mutations to imatinib resistance in different subsets of Philadelphia positive patients: by the GIMEMA Working Party on Chronic Myeloid Leukemia. Clin Cancer Res. 2006; 12: 7374-7379. 